\title{
A formação do profissional nutricionista na percepção do docente
}

\author{
Maria Mercês de Araújo Luz ${ }^{(a)}$ \\ Amanda Batista da Rocha Romero(b) \\ Ana Karolinne da Silva Brito ${ }^{(c)}$ \\ Lívia Patrícia Rodrigues Batista(d) \\ Lídya Tolstenko Nogueira ${ }^{(e)}$ \\ Marize Melo dos Santos ${ }^{(f)}$
}

Maria do Carmo de Carvalho e Martins ${ }^{(\mathrm{g})}$

Luz MMA, Romero ABR, Brito AKS, Batista LPR, Nogueira LT, Santos MM, et al. Professional nutritionists education from the perception of the teacher. Interface (Botucatu). 2015; 19(54):589-601.

This study evaluated the nutrition professionals education from the perception of nutrition teachers at a higher education institution in northeastern Brazil. This was a qualitative study among twenty nutrition teachers who were giving classes within disciplines in the professional cycle between 1980 and 2008. The main limitations faced were deficiencies in physical infrastructure, material and equipment, especially for conducting practical classes. Limitations relating to teaching activities and the knowledge acquired by students were mentioned. In spite of the difficulties, structural improvements were reported. Additional adjustments to infrastructure are required, along with measures aimed at better planning of teaching work and greater awareness among students regarding their role in the teaching-learning process, thereby enabling the education of professionals who are better qualified for the labor market.

Keywords: Higher education. Teachers. Nutritionist.
Este estudo avaliou a formação do profissional de nutrição na percepção dos docentes nutricionistas de uma instituição de Ensino Superior do nordeste brasileiro. Trata-se de pesquisa qualitativa realizada com vinte professores nutricionistas que ministraram disciplinas do ciclo profissional no período de 1980 a 2008. A principal limitação foi a deficiência de infraestrutura física, de material e de equipamentos, sobretudo para a realização de aulas práticas. Limitações relacionadas à atividade docente e ao conhecimento adquirido pelos estudantes foram mencionadas. Apesar das dificuldades apontadas, melhorias estruturais foram referidas. Adequações adicionais são necessárias na infraestrutura, bem como medidas voltadas para melhor planejamento do trabalho docente e para conscientização do corpo discente do seu papel no processo ensino-aprendizagem, possibilitando a formação de profissionais mais capacitados para o mercado de trabalho.

Palavras-chave: Educação superior. Docentes. Nutricionista.

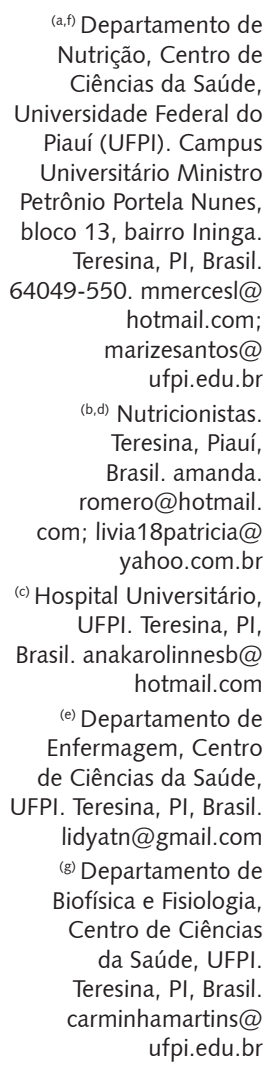

$(a, f)$ Departamento de Nutrição, Centro de Ciências da Saúde, Universidade Federal do Piauí (UFPI). Campus Universitário Ministro Petrônio Portela Nunes, bloco 13, bairro Ininga. Teresina, PI, Brasil. 64049-550.mmercesl@ hotmail.com; marizesantos@ ufpi.edu.br

(b,d) Nutricionistas. Teresina, Piauí, Brasil. amanda. romero@hotmail. com; livia18patricia@ yahoo.com.br (c) Hospital Universitário, UFPI. Teresina, PI, Brasil. anakarolinnesb@ hotmail.com

(e) Departamento de Enfermagem, Centro de Ciências da Saúde, UFPI. Teresina, PI, Brasil. lidyatn@gmail.com (g) Departamento de Biofísica e Fisiologia, Centro de Ciências da Saúde, UFPI. Teresina, PI, Brasil. carminhamartins@ ufpi.edu.br 


\section{Introdução}

O processo de formação de nutricionistas no Brasil, idealizado pela primeira geração de médicos nutrólogos, teve seu início com a criação do primeiro curso, em 1939, no Instituto de Higiene de São Paulo'. Em 2008, existiam 369 cursos de Nutrição, sendo a maior concentração destes na região sudeste, com 212 cursos². $^{2}$.

Segundo as Diretrizes Curriculares Nacionais (DCN) para o curso de graduação em Nutrição, o profissional nutricionista, com formação generalista, humanista e crítica, deve estar capacitado a atuar visando a segurança alimentar e a atenção dietética, em todas as áreas do conhecimento em que alimentação e nutrição sejam importantes para a promoção, manutenção e recuperação da saúde e para a prevenção de doenças de indivíduos ou grupos populacionais, contribuindo para a melhoria da qualidade de vida. Essa atuação deve ser pautada em princípios éticos, com reflexão sobre a realidade econômica, política, social e cultural ${ }^{3}$.

O corpo docente é um dos elementos centrais na formação do nutricionista, constituindo o alicerce fundamental sobre o qual devem ser instituídas as bases das mudanças necessárias a sua formação. Por isso, a discussão do ensino de Nutrição e a formação do nutricionista devem incluir questões como a formação docente e as práticas educativas empreendidas 4 .

As universidades devem estar preparadas para manter seus cursos e garantir condições adequadas para o ensino na graduação. Contudo, o cenário da formação profissional em universidades públicas brasileiras, apesar dos esforços dos trabalhadores da educação, aponta para um estado crônico de dificuldades em gerenciar os processos de trabalho, seja do ponto de vista dos ambientes, da remuneração ou do reconhecimento social desse trabalho ${ }^{5}$. Nesse sentido, avaliações positivas e negativas sobre as condições do ambiente laboral podem ser feitas pelo trabalhador a partir do seu envolvimento com o trabalho, sua satisfação e comprometimento ${ }^{6}$.

Poucos estudos têm investigado a prática pedagógica, seja no Ensino Básico, na graduação ou pós-graduação. Entre as limitações na prática docente apontadas em alguns trabalhos, encontram-se: salário, dicotomia teoria/prática e desvalorização da profissão ${ }^{7}$, falta de estrutura física de laboratórios para as práticas ${ }^{8}$, falta de equipamentos ${ }^{9}$, excesso de carga horária e sobrecarga de atividades ${ }^{1,9}$. Desse modo, o objetivo deste estudo foi avaliar a formação do profissional de nutrição na percepção dos docentes nutricionistas de uma instituição de Ensino Superior do nordeste brasileiro.

\section{Metodologia}

O estudo, de abordagem qualitativa, contou com a participação de vinte professores nutricionistas do Departamento de Nutrição da Universidade Federal do Piauí (UFPI), do Campus Universitário da cidade de Teresina, sendo 17 docentes em exercício profissional e três aposentados que, de acordo com a matriz curricular, ministraram disciplinas do ciclo profissional, ou seja, disciplinas específicas do curso ministradas exclusivamente por nutricionistas, no período de 1980 a 2008. Esse período compreende o início das disciplinas do ciclo profissional da primeira turma do curso de Nutrição da instituição até a criação do programa de pós-graduação em Alimentos e Nutrição.

A estrutura do currículo do curso da UFPI acompanhou a evolução histórica da formação do profissional de nutrição no âmbito nacional, e passou por três currículos. Desde 2006, com a aprovação do Projeto Pedagógico do Curso (PPC), em consonância com as DCN do curso de nutrição, está em vigor o Currículo quatro, que consta de 3.945 horas $^{10}$.

Os dados foram obtidos entre março e agosto de 2011, por meio de entrevista semiestruturada em que foram solicitadas informações sobre: dados pessoais do entrevistado, aspectos relativos à formação profissional e dificuldades na prática docente. As entrevistas foram gravadas com a permissão dos participantes e, posteriormente, transcritas na íntegra.

Após a coleta, os dados foram organizados e as opiniões dos participantes analisadas tendo como referencial, para o tratamento dos dados, a análise de conteúdo ${ }^{11}$. Foi realizada pré-análise do conteúdo considerando os critérios: exaustividade, representatividade, homogeneidade e pertinência. 
O tratamento dos dados, a inferência e interpretação foram realizados após categorização baseada na classificação dos elementos segundo semelhanças e diferenças, com posterior reagrupamento em função de características comuns.

Para efeito de apresentação dos resultados e para garantir o anonimato dos sujeitos da pesquisa, foi utilizada, como código, a letra $\mathrm{S}$ seguida do número de ordem da entrevista, para cada participante.

O estudo foi aprovado pelo Comitê de Ética em Pesquisa da UFPI e está em concordância com a Resolução n 466/2012 do Conselho Nacional de Saúde/Ministério da Saúde ${ }^{12}$. Os participantes foram informados sobre os objetivos e metodologia da pesquisa e assinaram Termo de Consentimento Livre e Esclarecido.

\section{Resultados e discussão}

Na Tabela 1, é apresentada a distribuição dos vinte docentes do curso de nutrição participantes do estudo, segundo faixa etária e aspectos relacionados à formação acadêmica e exercício de magistério Superior.

Tabela 1. Distribuição dos docentes do curso de nutrição da Universidade Federal do Piauí, Campus de Teresina, segundo faixa etária e aspectos relacionados à formação acadêmica e exercício profissional no magistério Superior

\begin{tabular}{|c|c|c|}
\hline Variável & $\mathrm{N}$ & $\%$ \\
\hline \multicolumn{3}{|l|}{ Faixa etária (anos) } \\
\hline $30-39$ & 02 & 10,0 \\
\hline $40-49$ & 07 & 35,0 \\
\hline $50-59$ & 10 & 50,0 \\
\hline 60 ou mais & 01 & 5,0 \\
\hline \multicolumn{3}{|c|}{ Tempo (anos) de conclusão do curso de graduação em Nutrição } \\
\hline$<10$ & 01 & 5,0 \\
\hline 10 a 19 & 01 & 5,0 \\
\hline 20 a 29 & 13 & 65,0 \\
\hline 30 a 39 & 04 & 20,0 \\
\hline$\geq 40$ & 01 & 5,0 \\
\hline \multicolumn{3}{|c|}{ Instituição de Ensino Superior em que concluiu o curso de graduação } \\
\hline Universidade Estadual do Ceará & 01 & 5,0 \\
\hline Universidade Federal da Paraíba & 01 & 5,0 \\
\hline Universidade Federal de Pernambuco & 06 & 30,0 \\
\hline Universidade Federal do Piauí & 11 & 55,0 \\
\hline Universidade Estadual do Rio de Janeiro & 01 & 5,0 \\
\hline \multicolumn{3}{|l|}{ Titulação ao ingressar no magistério Superior } \\
\hline Graduação & 11 & 55,0 \\
\hline Especialização & 05 & 25,0 \\
\hline Mestrado & 03 & 15,0 \\
\hline Doutorado & 01 & 5,0 \\
\hline \multicolumn{3}{|l|}{ Tempo de docência na UFPI (anos) } \\
\hline$<10$ & 03 & 15,0 \\
\hline $10-19$ & 06 & 30,0 \\
\hline $20-29$ & 10 & 50,0 \\
\hline$\geq 30$ & 01 & 5,0 \\
\hline \multicolumn{3}{|l|}{ Titulação em 2008} \\
\hline Especialização & 06 & 30,0 \\
\hline Mestrado & 09 & 45,0 \\
\hline Doutorado & 05 & 25,0 \\
\hline \multicolumn{3}{|l|}{ Regime de Trabalho: } \\
\hline TP - 20 horas & 01 & 5,0 \\
\hline $\mathrm{TI}-40$ horas & 01 & 5,0 \\
\hline Dedicação Exclusiva & 18 & 90,0 \\
\hline
\end{tabular}


Todos os docentes eram do sexo feminino, e metade encontrava-se na faixa etária de cinquenta a 59 anos. A maioria (65\%) dos docentes tinha concluído o curso vinte a 29 anos antes da realização do estudo, mais de metade (55\%) concluiu o curso de graduação na UFPI e ingressou no magistério Superior sem ter curso de pós-graduação. Metade dos participantes tinha tempo de magistério Superior entre vinte e 29 anos, sendo o menor tempo de atividade docente igual a seis anos, e o maior, igual a 31 anos. A maioria (90\%) dos participantes referiu regime de trabalho em dedicação exclusiva. Quanto à titulação, $70 \%$ dos docentes informaram possuir mestrado (25\%) ou doutorado (45\%).

Para melhor entendimento das dificuldades encontradas pelos docentes, foram identificadas três categorias de dificuldades, as quais emergiram da análise das informações fornecidas pelos entrevistados, sendo elas: dificuldades estruturais, dificuldades relacionadas às atividades docentes, e dificuldades relacionadas ao embasamento teórico e maturidade dos discentes.

\section{Dificuldades estruturais}

Dificuldades estruturais foram referidas por $60 \%$ dos entrevistados, e as mais citadas incluíram a carência de material e equipamentos, e estrutura insatisfatória de laboratórios para a realização de aulas práticas. Limitações estruturais podem ser evidenciadas nos trechos de entrevistas transcritos a seguir.

"[...] as dificuldades quando ingressei foram aquelas dificuldades de ordem estrutural física e funcional." S1

“[...] Então a dificuldade é essa: o espaço físico é insuficiente, a questão do material pra gente realizar..." S5

“[...] o laboratório de diagnóstico nutricional, [...] não acompanha a demanda do departamento. Nós temos ' $n$ ' projetos de pesquisa, atividades de sala de aula e, sobretudo, atividades de pesquisa e extensão que precisam desses equipamentos, [...] não estão disponíveis em quantidade suficiente para atender essa demanda." S9

Nos últimos anos, ocorreram iniciativas do governo brasileiro para melhorar a educação pública federal, sendo uma delas o REUNI (Programa de Apoio a Planos de Reestruturação e Expansão das Universidades Federais), com a proposta de possibilitar a oferta de recursos para ampliação de estruturas físicas e tecnológicas e contratação de docentes e técnicos ${ }^{13}$. Segundo Lima ${ }^{14}$, essa iniciativa gerou aumento no número de matrículas nos cursos presenciais, com superlotação de salas de aula e alocação de recursos insuficientes para continuar a expansão. Na UFPI, a adesão ao REUNI viabilizou: a criação de novos cursos, contratação de professores, reformas e construções, melhorando a estrutura física da IES, e aquisição de livros e de equipamentos.

As disciplinas do Ciclo Básico do curso de Nutrição da UFPI são ministradas, desde sua criação, utilizando instalações físicas e equipamentos existentes para a área básica dos cursos da área da saúde. O espaço físico do Departamento de Nutrição passou por três grandes reformas físicas, inclusive com aquisição de equipamentos. Em 2008, o curso passou a contar com: cinco salas de aula, oito laboratórios, um auditório, dez salas para professores, entre outros espaços ${ }^{10}$.

Limitações de espaço físico também foram dificuldades encontradas em estudos realizados em outras instituições brasileiras. Em pesquisa conduzida com docentes nutricionistas do Paraná, foi referida falta de disponibilidade de locais para práticas, tais como hospitais e clínicas escolas ${ }^{8}$. A falta de estrutura no trabalho foi um dos principais problemas citados por professores de educação física da rede estadual de Caratinga, $\mathrm{MG}^{7}$. Em estudo com professores da Universidade Federal do Mato Grosso do Sul, foi encontrada insatisfação relacionada com a falta de equipamentos e com baixo estado de conservação dos prédios, sendo uma prática comum a aquisição de materiais por meio de recursos de projetos financiados ou, mesmo, utilizando recursos próprios 9 . 
Entre os fatores citados como causas das dificuldades estruturais, estavam os elevados custos dos equipamentos, burocracia na aquisição de material e equipamentos, e carência de técnicos, conforme pode ser evidenciado abaixo:

“[...] a gente tem uma certa dificuldade ainda em relação a manter as aulas práticas porque você tem um custo de ter um técnico que possa ajudar [...] a gente sabe que há toda uma burocracia até chegar algum conserto, alguma manutenção [...]". S3

“[...] essa limitação de laboratório; as práticas... elas nos deixavam uma lacuna muito grande. Então só aqueles que realmente queriam, que iam atrás, que tinham que ir buscar com suas próprias pernas". S2

“[...] às vezes a gente até pensava em colocar no plano de ensino determinadas aulas práticas. Entretanto, não colocávamos por dificuldade de executá-las devido à falta de equipamentos". S6

Material, equipamentos e estrutura física são necessários para a formação, não apenas do profissional nutricionista como dos outros profissionais da área de saúde. É importante destacar que os materiais são usados com o objetivo de "chamar a atenção" dos alunos, servindo para "quebrar" a rotina de sala da aula ${ }^{15}$. Durante a execução de atividades experimentais, o aluno constrói seu conhecimento por meio da interação com os objetos estudados, possibilitando melhor apreensão dos conteúdos trabalhados. A falta de equipamentos, de materiais e de estrutura física adequados prejudica o aprendizado e dificulta o desenvolvimento do trabalho docente. Na tentativa de sanar o problema, algumas vezes, são utilizados materiais reciclados ou adaptados que não fornecem precisão científica e podem implicar a não-apropriação devida de conceitos científicos e pedagógicos.

Em trabalho realizado na Universidade Federal do Paraná, com professores com formação em pediatria e nutrição, afirmações feitas pelos nutricionistas de dificuldade em aliar teoria e prática reforçam a ideia de que a dicotomia entre esses dois processos constitui elemento complicador do bom desempenho profissional ${ }^{16}$. A separação entre o ensino e a pesquisa nas universidades brasileiras, bem como a valorização da pesquisa em detrimento do ensino (de graduação) no meio acadêmico, foram relatados por Diniz-Pereira ${ }^{17}$ como um fator causador de enormes prejuízos à formação profissional.

O mundo do trabalho mudou, exigindo do profissional melhor qualificação para que seja capaz de criar e produzir mais em menos tempo, e possibilitar melhor aplicação de recursos ${ }^{18}$. Para estar apto a atender a demanda desse mercado competitivo, ao longo de sua formação profissional, o estudante precisa desenvolver habilidades que o tornem capaz de realizar suas atividades dentro dos mais altos padrões de qualidade. Assim, maiores investimentos em materiais, equipamentos e estrutura física são necessários para assegurar boa formação profissional e atender ao mercado de trabalho.

As DCN do curso de nutrição recomendam a realização das atividades teóricas e práticas de forma integrada, presentes desde o início do curso, e permeando toda a formação do nutricionista ${ }^{3}$. Isso porque o estudante que é inserido no ambiente de trabalho aprende com situações concretas por meio da experiência prática, o que contribui para a atuação com maior resolubilidade e efetividade ${ }^{19}$. A falta de estrutura para realização dessas atividades compromete a formação profissional.

Em pesquisa com docentes de Cursos de Licenciatura da Universidade Federal do Triângulo Mineiro e da Universidade Federal Uberlândia, os professores apontaram a expansão do número de vagas das universidades públicas combinada com o reduzido recurso financeiro investido e falta de garantia de continuidade de investimentos como um fator complicador, trazendo como consequências: a falta de infraestrutura e o improviso na formação docente e no desenvolvimento de suas atividades ${ }^{20}$.

Apesar das dificuldades apontadas, neste estudo, mais de um terço dos docentes entrevistados (35\%) referiu que modificações importantes foram percebidas entre 1980 e 2008, evidenciando melhorias na infraestrutura física, nos equipamentos e materiais ao longo do período de vínculo com a Instituição. Esses avanços são evidenciados nos posicionamentos apresentados: 
“Nós não tínhamos laboratórios, hoje já tem laboratórios na área de Nutrição Experimental e Bromatologia, que estão muito mais equipados, apesar de que ainda precisa desenvolver mais $[\ldots]^{\prime \prime} . \mathrm{S} 1$

“[...] a questão de livros, do material didático, hoje está muito mais fácil. [...] você percebe mudanças muito positivas, sobretudo no nosso departamento. [...] Claro que precisa de muitas melhorias [...] a gente já conseguiu muito em termos de adequação de espaço físico, de equipamentos, de laboratórios [...]". S7

“[...] eu dei aula lá na Física levando retroprojetor, hoje se dá aula com Datashow, [...] com ar condicionado [...]". S14

“[...] ao longo da trajetória do curso, muitos aspectos foram melhorados como a ampliação da área física para administração do curso, salas de aula e laboratórios [...]". S18

$\mathrm{Na}$ opinião de alguns professores, uma perspectiva que pode contribuir para melhorar a infraestrutura está relacionada com o estímulo para o desenvolvimento de projetos de pesquisas e incentivo à qualificação do corpo docente, conforme destacado nas transcrições a seguir.

“[...] com o que está sendo gerado em termos de publicação, isso vai nos permitir um currículo mais competitivo, para que a gente possa concorrer junto às agências de fomento, a exemplo do CNPq, para que se consigam mais recursos e se amplie mais ainda a infraestrutura para pesquisa e pós-graduação". S2

“[...] elaboramos alguns projetos de pesquisa, entretanto, os mesmos não foram financiados pelo MEC com a justificativa da falta de professores com titulação de Mestres ou Doutores [...]. Diante desse quadro, passou-se a incentivar os professores a buscarem a Pós-Graduação e com a ampliação do quadro docente, tão logo foi possível, o Departamento liberou professor para realizar Mestrado, passando então a ser uma política adotada por esse setor". S6

O financiamento da educação brasileira é previsto em lei, sendo o Governo Federal o principal financiador das instituições federais de Ensino Superior ${ }^{21}$. E apenas pequena parcela dos custos é mantida por meio da arrecadação própria de cada instituição, sendo fruto de seus próprios esforços em adquirir recursos, tais como projetos financiados por agências de fomento à pesquisa ${ }^{22}$. Fica evidente que a responsabilidade de manter todo o aparato necessário ao ensino é da universidade, e não do docente. As universidades devem estar preparadas para manter seus cursos e garantir, aos docentes e discentes, condições adequadas para o ensino.

Segundo as DCN, deve existir articulação entre ensino, pesquisa e extensão/assistência ${ }^{3}$. Assim, os projetos financiados são importantes para auxiliar os pesquisadores com equipamentos, reagentes e materiais para garantir o desenvolvimento da pesquisa, também necessária para uma boa formação profissional. E a qualificação do professor é necessária tanto para o desenvolvimento das atividades de ensino, pesquisa e extensão quanto para aumentar as chances de conseguir investimentos das agências de fomento para financiamento de projetos de pesquisa.

\section{Dificuldades relacionadas a atividades docentes}

Número reduzido de docentes foi uma dificuldade referida por 35\% dos entrevistados. Na opinião desses docentes, essa limitação causa sobrecarga de atividades, redução do tempo disponível para pesquisa e extensão, e resulta em comprometimento do desempenho. Ademais, segundo eles, a prática docente é dificultada pela carga horária excessiva em sala de aula instituída por reformas curriculares, e também pela burocracia no trabalho. Esses aspectos podem ser evidenciados nos relatos transcritos. 
"[...] a gente tem colocado certa dificuldade pelo número de professores, [...] com a reforma Curricular aumentou muito a carga horária do professor". S8

"Agora, tem muita dificuldade: burocracia, o professor ficar muito envolvido com questões administrativas, quando deveria ficar, ter mais tempo, do seu tempo na instituição, voltado mesmo para estudar, para o ensino e a pesquisa, e fazer extensão [...] tudo é o professor que tem que fazer. Então, como ele fica sobrecarregado de tarefas, que o afastam do tempo que ele teria que se dedicar a docência". S17

Excesso de carga horária e sobrecarga de atividades foram referidos como aspectos negativos na prática docente em outros trabalhos. Em estudo realizado na Universidade Federal do Mato Grosso do Sul, a maioria dos professores referiu excesso de carga horária, e insuficiência de apoio administrativo no gerenciamento de atividades relacionadas aos recursos financeiros de projetos de pesquisa, como: compra de material, manutenção de equipamentos e atividade de laboratório ${ }^{9}$. Esses fatores podem contribuir para o desgaste do professor, além de ocuparem um tempo que poderia ser dedicado às atividades acadêmicas. O professor de Ensino Superior tem como atribuições desenvolver atividades de ensino, pesquisa e extensão, com prioridade para o ensino. A falta de docentes e de pessoal de apoio acarreta a sobrecarga de atividades, comprometendo a formação dos discentes, sobretudo na pesquisa e extensão.

O avanço tecnológico oriundo do desenvolvimento de novas tecnologias, especialmente de informação e comunicação e de novos métodos de gestão do trabalho e organização da produção, exige profissionais cada vez mais qualificados ${ }^{23}$. Para Santos ${ }^{24}$, estar qualificado é deter novos conhecimentos e habilidades exigidos pelo mercado de trabalho. E a falta de tempo para capacitar o professor também compromete a formação do discente pela falta de capacitação docente. Assim, o trabalho docente deve ser planejado de modo a minimizar a carga de atribuições para os professores e evitar o comprometimento da qualidade do seu trabalho.

O curso de nutrição da UFPI nos anos de 1978 e 1979 oferecia trinta vagas anuais com uma entrada; em 2007, passou a oferecer oitenta vagas. E, desde 1980, as vagas ofertadas passaram a ser distribuídas com metade em cada semestre letivo. Quanto ao corpo docente, em 1982, na conclusão da primeira turma, havia onze docentes nutricionistas; e, em 2008, o curso contava com vinte professores, sendo mais de metade (55\%) de egressos da UFPI. No que diz respeito à titulação: em $1982,64 \%$ possuíam apenas o curso de graduação, $18 \%$ eram especialistas e $18 \%$ eram mestres; em $2008,45 \%$ eram mestres, $25 \%$ doutores e $30 \%$ especialistas ${ }^{10}$.

Analisando a evolução do referido curso, observou-se aumento de $167 \%$ no número de vagas ofertadas para o curso e de $81 \%$ no número de professores envolvidos nas disciplinas do ciclo profissional. Quanto à capacitação docente, houve marcante aumento na qualificação, variando de $18 \%$ dos professores com pós-graduação stricto sensu no período de formação da primeira turma para $70 \%$ em 2008.

O quadro de servidores técnicos e administrativos do Departamento de Nutrição em 2008 contava somente com dois funcionários: um técnico de laboratório, e um tecnólogo para dar apoio aos laboratórios de Bromatologia, Bioquímica de Alimentos e de Microbiologia e Controle de Qualidade de Alimentos. O restante dos servidores eram terceirizados e bolsistas sem qualificação para o desenvolvimento de grande parte das atividades administrativas ${ }^{10}$.

Em estudo realizado por Silvério et al. ${ }^{1}$, sobre o ensino em cursos da área de saúde e sua repercussão na qualidade de vida do docente, os professores apontaram grande comprometimento na qualidade de vida pelo excesso de horas de trabalho. E Santini e Molina Neto ${ }^{25}$ verificaram que professores de educação física de Porto Alegre sentiam-se sobrecarregados no trabalho, por fatores como: a multiplicidade de papéis, a falta de organização, o número de alunos para atender, o número de horas dedicadas à prática docente, a falta de tempo para se qualificar, e as precárias condições materiais oferecidas pelas escolas públicas. 
Tani $^{26}$ enfatiza que, para que as atividades de ensino, pesquisa e extensão sejam realizadas com eficiência, é necessário um suporte de estruturas administrativas que priorizem a qualidade. Esse suporte constitui um importante fator de qualidade no ensino de Graduação - exigindo constante investimento nos setores administrativos, financeiros, tecnológicos e de recursos humanos, que, no entanto, é frequentemente subestimado no âmbito universitário.

Borges $^{20}$ destaca que, com a expansão de vagas nas universidades públicas, ocorreu o crescimento desordenado do número de matrículas nos últimos anos, acarretando sobrecarga de aulas, excesso de disciplinas e elevado número de alunos por turma. E, como a contratação de docentes não acompanhou o crescimento das vagas disponibilizadas nas universidades, o número de docentes fica insuficiente para a demanda, o que os deixa sobrecarregados, impossibilitando-os de conciliar ensino, pesquisa e extensão, e preparar suas aulas com qualidade.

As DCN do curso de nutrição salientam que o trabalho do nutricionista deve estar fundamentado na capacidade de tomar decisões e, para tanto, o profissional deve possuir competências e habilidades para avaliar, sistematizar e decidir as condutas mais adequadas, baseadas em evidências científicas ${ }^{21}$. Assim, o projeto pedagógico do curso deve ser centrado no estudante como sujeito da aprendizagem, e apoiado no professor como facilitador e mediador do processo ensino-aprendizagem, buscando a formação integral e adequada do estudante ${ }^{3}$. Considerando que o discente é o centro do processo ensino-aprendizagem, o estudante deve ser inserido no ambiente de trabalho desde o início do curso, para que vivencie os cenários reais de prática e com os profissionais, reforçando a exigência de integração entre a teoria e a prática (saber e fazer), o que, também, torna necessário o aumento do número de docentes, visando contribuir para uma boa formação profissional.

\section{Dificuldades relacionadas ao embasamento teórico e maturidade dos discentes}

Quanto às dificuldades relacionadas ao corpo discente, para 15\% dos entrevistados, existe dificuldade, por parte dos estudantes, em aprofundar seus conhecimentos e em redigir textos, o que pode ser evidenciado nos trechos transcritos.

"[...] o nosso corpo discente ainda tem dificuldade de acompanhar o aprofundamento do conhecimento que é levado para eles. [...] eles têm muito acesso à informação, até porque o conhecimento do mundo digital agora facilita isso, mas por ter acesso a variados conjuntos de conhecimento e de informação, ele têm uma dificuldade de se aprofundar. Não se aprofundando, ele não traz o retorno". S10

"Agora o grande perigo nosso é o 'ctrl C, ctrl V e ctrl B'. Essa questão de você mandar fazer trabalho; isso é seríssimo, porque hoje é difícil, o aluno não sabe mais redigir por ele mesmo". S11

Outra dificuldade mencionada em relação ao corpo discente diz respeito à dedicação dos alunos nas disciplinas, sendo uma dificuldade na prática docente mostrar, aos alunos, que eles não devem dedicar-se apenas àquelas disciplinas que, em princípio, julguem mais interessantes.

"[...] com certeza foi a única dificuldade que eu senti: de fazer entender que eles tinham que se preparar para qualquer desafio e não só para o que eles estavam escolhendo". S12

De modo semelhante, em estudo desenvolvido com professores nutricionistas do Paraná, metade dos docentes salientaram a dificuldade de aprendizagem dos alunos que não estavam preparados para a leitura, reflexão e discussão dos temas trabalhados ${ }^{27}$.

Esses aspectos reforçam a importância do discente no seu próprio desenvolvimento acadêmico, uma vez que o aluno faz parte do processo de ensino aprendizagem, juntamente com a instituição e o professor, e deve possuir requisitos importantes que influenciam diretamente nesse processo, tais como: capacidade, experiência anterior, disposição, boa vontade e interesse ${ }^{28}$. Segundo $\operatorname{Tani}^{26}$, para que o corpo discente assuma o papel de protagonista do processo ensino-aprendizagem, é necessária 
mudança de mentalidade, tornando-se mais crítico e com mais iniciativa. Além disso, o estudante precisa ter consciência de que está se tornando gradativamente um profissional, o que envolve um processo gradual de amadurecimento, que deve ser iniciado o mais precocemente possível.

As mudanças no mundo do trabalho exigem um novo perfil do profissional, com capacidade de identificar e resolver problemas, fazer diagnósticos e estar preparado para atuar em contextos de constantes mudanças. Por sua vez, o docente deve ser um agente de transformação, cuja função é contribuir para a formação de profissionais capazes de aprender continuamente e de construir conhecimentos voltados para promover a qualidade de vida das pessoas. Sua preocupação deve ser propiciar, ao estudante, condições de refletir acerca de: sua postura, responsabilidades, mudanças e possibilidades, desenvolvendo sua capacidade de pensamento, reflexão, análise e síntese. Assim, o estudante pode tornar-se apto a acompanhar as mudanças no mercado de trabalho na mesma velocidade em que elas ocorrem ${ }^{18,29}$. Para isso, os docentes devem estar capacitados para despertar o interesse nos discentes, auxiliados por novas metodologias de ensino e pela sua inserção no processo de trabalho das equipes, para que eles possam construir novos conhecimentos e serem agentes transformadores da realidade.

Cunha $^{30}$ enfatiza que não há uma preocupação significativa com os conhecimentos pedagógicos, uma vez que se pressupõe que os estudantes do Ensino Superior possuem maturidade para responder às exigências da aprendizagem nesse nível. Entretanto, segundo Esperidião e Munari31, a idade dos alunos, ao ingressarem na Universidade, é cada vez menor e, muitos deles encontram-se em pleno desenvolvimento e apresentam uma série de expectativas e desejos que, algumas vezes, não condizem com a realidade esperada tanto em relação ao curso quanto em relação às condições de ensino. Essas experiências influenciam os pensamentos, sentimentos e ações dos alunos, e nem sempre são levadas em consideração pelas instituições de Ensino Superior.

Em estudo sobre as limitações na formação do enfermeiro, Pinto e Pepe ${ }^{32}$ destacaram que apesar de alguns docentes citarem como características desejáveis dos alunos: a condição de um cidadão e profissional criativo, participativo, crítico, ético, questionador e interativo, a prática pedagógica desenvolvida na abordagem tradicional de ensino dificulta ou, mesmo, impede o desenvolvimento desses traços.

Embora os professores aprofundem seus conhecimentos em sua área de atuação específica, muitas vezes, pode faltar-Ihes conhecimento científico sobre o processo de ensino-aprendizagem ${ }^{29}$. Nesse contexto, Silva e Rodrigues ${ }^{33}$ observaram que graduandos de enfermagem de uma universidade pública, após avaliarem aulas de determinados professores, apesar de ressaltarem sua competência técnica, referiram falta de didática, e excesso de aulas expositivas com participação mínima dos alunos. Ademais, os autores enfatizaram que a utilização de estratégias de ensino não convencionais é importante no processo ensino-aprendizagem por ser um meio atrativo que propicia melhor assimilação do conteúdo.

Não existe uma pedagogia perfeita para ser desenvolvida em todos os momentos e para todos os conteúdos. As estratégias pedagógicas são meios utilizados pelos docentes na articulação do processo de ensino para estimular o aprendizado. Em princípio, todas podem ser utilizadas, uma vez que a estratégia de ensino-aprendizagem depende dos objetivos estabelecidos pelo professor e das habilidades a serem desenvolvidas em cada série de conteúdo. A habilidade do professor em identificar essas diferenças e escolher o método mais adequado para cada situação é determinante para o sucesso no processo de educar ${ }^{34}$. Assim, torna-se evidente a necessidade da reflexão crítica na construção do conhecimento, de modo a definir o objetivo desejado com essa construção e como utilizá-lo para a transformação da realidade.

A maioria dos docentes do Ensino Superior não tem formação para serem professores, mas, sim, para exercerem com qualidade a sua profissão como técnicos. E, mesmo para docentes com mestrado e doutorado, falta um conjunto de conhecimentos e práticas para trabalharem como facilitadores do processo ensino-aprendizagem. Neste sentido, Figueiredo ${ }^{35}$ refere que, no Brasil, a formação dos quadros docentes é a causa estrutural mais importante dentre aquelas que produzem as carências quantitativas e qualitativas do sistema educacional. Portanto, é necessária a institucionalização da educação permanente, de modo a contribuir para que estes melhorem suas práticas de docência. 
Apesar das limitações relacionadas aos discentes anteriormente exploradas, também foram observados relatos que definem os estudantes como "comprometidos", "dedicados" e "com boa formação básica". Esses aspectos são resumidos no trecho transcrito abaixo:

“[...] nós estamos em uma instituição federal pública e que os alunos que ingressam são os que têm uma melhor formação colegial, porque são os que tiram as melhores notas, que conseguem mais pontos [...] são aqueles que têm uma base fundamental melhor [...] Além disso, eles são comprometidos, são empenhados, são interessados pelo curso". S3

A análise dos resultados demonstra, ao longo da trajetória do curso, por um lado, aspectos positivos relacionados com melhorias estruturais e de material didático, compromisso e qualificação do corpo docente, e interesse e nível intelectual dos alunos; e, por outro, que a principal dificuldade enfrentada por grande parte dos docentes envolve infraestrutura física, de material e equipamentos ainda insuficientes, sobretudo para aulas práticas, seguida pela sobrecarga de atividades na prática docente e por preocupações com o conhecimento adquirido pelo corpo discente.

Ressalta-se que, além da necessidade de adequações na infraestrutura para o ensino, devem ser implementadas medidas voltadas para melhor planejamento do trabalho docente e maior reflexão dos professores quanto às suas habilidades e práticas pedagógicas, bem como a institucionalização da educação permanente para a formação dos professores. Essas medidas poderão contribuir para a mudança na abordagem do ensino, para que os estudantes, como sujeitos de sua aprendizagem, tornem-se mais criativos, participativos, críticos, éticos, questionadores e interativos, e, dessa maneira, sejam formados profissionais mais capacitados para o mercado de trabalho.

\section{Colaboradores}

Maria Mercês de Araújo Luz participou na concepção e delineamento do estudo; coleta, processamento, análise e interpretação dos dados; pesquisa bibliográfica e elaboração do manuscrito. Amanda Batista da Rocha Romero, Ana Karolinne da Silva Brito, e Lívia Patrícia Rodrigues Batista participaram no processamento, análise e interpretação dos dados; pesquisa bibliográfica e elaboração do manuscrito. Lídya Tolstenko Nogueira e Marize Melo dos Santos participaram na interpretação dos dados; pesquisa bibliográfica e revisão do conteúdo intelectual do manuscrito. Maria do Carmo de Carvalho e Martins participou como responsável por todos os aspectos do trabalho. Participou na concepção e delineamento do estudo, análise e interpretação dos dados, elaboração e revisão crítica do manuscrito. Todos os autores aprovaram a versão final do manuscrito e declaram serem responsáveis por todos os aspectos do trabalho, garantindo sua precisão e integridade

\section{Agradecimentos}

À professora Dra. Maria do Socorro Silva Alencar, pelas contribuições em relação à técnica de análise dos dados da pesquisa. 


\section{Referências}

1. Silvério $M R$, Patrício $Z M$, Brodbeck $I M$, Grosseman S. O ensino na área da saúde e sua repercussão na qualidade de vida docente. Rev Bras Educ Med. 2010; 34(1):65-73.

2. Calado CLA. Relação de endereços dos cursos de nutrição no Brasil [Internet]. 2009 [acesso 2015 Fev 9]. Disponível em: http://www.cfn.org.br/novosite/arquivos/ESCOLANUTRI\% C3\% 87AO-AGOSTO-2009.pdf

3. Conselho Nacional de Educação. Câmara de Educação Superior. Resolução CNE/CES n 5, de 07 de novembro de 2001. Institui Diretrizes Curriculares Nacionais do Curso de Graduação em Nutrição. Diário Oficial da União. 9 Nov 2001; Seção 1.

4. Costa NMSP. Formação pedagógica de professores de nutrição: uma omissão consentida? Rev Nutr. 2009; 22(1):97-104.

5. Cruz RM, Lemos JC. Atividade docente, condições de trabalho e processos de saúde. Motrivivencia. 2005; 24(17):59-80.

6. Kanan LA, Zanelli JC. Envolvimento de docentes-gestores com o trabalho no contexto universitário. Psicol Soc. 2011; 23(1):56-65.

7. Gonçalves ECF, Santos AEO, Martins Júnior JA. Prática docente: dificuldades encontradas pelos professores de educação física nos cinco primeiros anos de atuação profissional. Mundo Saude. 2007; 31(4):494-9.

8. Paraná SFP. A formação do nutricionista: sob o olhar da teoria e prática [dissertação]. Curitiba (PR): Pontifícia Universidade Católica do Paraná; 2004. [acesso 2011 Dez 20]. Disponível em: http://www.biblioteca.pucpr.br/tede/tde_arquivos/2/TDE-2005-0308T13:05:29Z-99/Publico/SimoneParanaEducacao.pdf

9. Lima MFEM, Lima-Filho DO. Condições de trabalho e saúde do/a professor/a universitário/a. Cienc Cogn. 2009; 14(3):62-82.

10. Luz MMA. Trajetória do curso de nutrição da Universidade Federal do Piauí: 1976 - 2008 [dissertação]. Teresina (PI): Universidade Federal do Piauí; 2012. [acesso 2015 Fev 10]. Disponível em: http://www.ufpi.br/subsiteFiles/ppgan/arquivos/files/ Dissertacao\%20Final\%20MSc_\%20Maria\%20Merces\%20de\%20Araujo\%20Luz.pdf

11. Bardin L. Análise de conteúdo. 4a ed. Lisboa: Edições 70; 2004.

12. Conselho Nacional de Saúde. Resolução n 466, de 12 de dezembro de 2012. Aprova as diretrizes e normas regulamentadoras de pesquisas envolvendo seres humanos. Diário Oficial da União. 13 Jun 2013; Seção 1.

13. Presidência da República. Casa Civil. Subchefia para Assuntos Jurídicos. Decreto $n^{\circ}$ 6.096, de 24 de abril de 2007. Institui o Programa de Apoio a Planos de Reestruturação e Expansão das Universidades Federais - REUNI [Internet]. Brasília (DF): Casa Civil; 2007 [acesso 2014 Fev 12]. Disponível em: http://www.planalto.gov.br/ccivil_03/_ato20072010/2007/decreto/d6096.htm

14. Lima PG. Políticas de educação superior no Brasil na primeira década do século XXI: alguns cenários e leituras. Avaliação (Campinas). 2013; 18(1):85-105.

15. Silva JA, Marinho JCB, Silva GR, Bartelmebs RC. Concepções e práticas de experimentação nos anos iniciais do ensino fundamental. Linhas Crit. 2012; 18(35):127-50.

16. Amorim STSP, Moreira H, Carraro TE. A formação de pediatras e nutricionistas: a dimensão humana. Rev Nutr. 2001; 14(2):111-8.

17. Diniz-Pereira JE. O ovo ou a galinha: a crise da profissão docente e a aparente falta de perspectiva para a educação brasileira. Rev Bras Estud Pedag. 2011; 92(230):34-51.

18. Almeida MM. A escassez de líderes no mercado de trabalho: o papel do professor universitário na formação deste profissional pode colaborar para a mudança do cenário atual. Gestao Soc. 2012; 1(1):1-9. 
19. Frenk J, Chen L, Bhutta ZA, Cohen J, Crisp N, Evans T, et al. Profesionales de la salud para el nuevo siglo: transformando la educación para fortalecer los sistemas de salud en un mundo interdependiente. Rev Peru Med Exp Salud Publica. 2011; 28(2):337-41.

20. Borges MC. Projetos de expansão das universidades públicas federais do triângulo mineiro e a formação inicial de professores. Debates Educ. 2011; 3(6):1-18.

21. Ministério da Educação. Lei n. 9.394, de 20 de dezembro de 1996. Estabelece as Diretrizes e Bases da Educação. Diário Oficial da União. 20 Dez 1996.

22. Duarte CS, Oliveira TSM. O financiamento das instituições federais de ensino superior: o caso da Universidade Federal de Goiás. Rev Organ Sist. 2012; 2(1):102-18.

23. Vieira $M$, Chinelli $F$. The contemporary relationship between work, qualification and recognition: repercussions on the Unified Health System (SUS) workers. Cienc Saude Colet. 2013; 18(6):1591-600.

24. Santos EA. Qualificação \& trabalho: reflexões sob a ótica da globalização. Rev Esp Dial Descon [Internet]. 2010; 2(2) [acesso 2015 Fev 13]. Disponível em: http://seer.fclar. unesp.br/redd/article/view/4153/3759

25. Santini J, Molina Neto V. A síndrome de esgotamento profissional em professores de educação física: um estudo na rede municipal de ensino de Porto Alegre. Rev Bras Educ Fis Esp. 2005; 19(3):209-22.

26. Tani G. Avaliação das condições do ensino de graduação em Educação Física: garantia de uma formação de qualidade. Rev Mackenzie Educ Fis Esp. 2007; 6(2):55-70.

27. Kopruszynski CP, Vechia A. A prática pedagógica dos nutricionistas que atuam na docência: desafios e perspectivas de mudanças. Quaestio. 2011; 13(1):81-97.

28. Santos SC. O processo de ensino-aprendizagem e a relação professor-aluno: aplicação dos "sete princípios para a boa prática na educação de ensino superior". Cad Pesqui Adm. $2001 ; 8(1): 69-82$.

29. Cavalcante LIP, Bissoli MF, Almeida MI, Pimenta SG. A docência no ensino superior na área de saúde: formação continuada e desenvolvimento profissional em foco. Rev Eletr Pesquieduca. 2011; 3(6):162-82.

30. Cunha MI. Diferentes olhares sobre as práticas pedagógicas no ensino superior: a docência e sua formação. Educ. 2004; 54(3):525-36.

31. Esperidião $E$, Munari DB. Holismo só na teoria: a trama de sentimentos do acadêmico de enfermagem sobre a sua formação. Rev Esc Enferm USP. 2004; 38(3):332-40.

32. Pinto JBT, Pepe AM. A formação do enfermeiro: contradições e desafios à prática pedagógica. Rev Latino-am Enferm. 2007; 15(1):120-6.

33. Silva RPG, Rodrigues RM. Mudança curricular: desafio de um curso de graduação em enfermagem. Rev Bras Enferm. 2008; 61(2):233-8.

34. Mazzioni S. As estratégias utilizadas no processo de ensino-aprendizagem: concepções de alunos e professores de ciências contábeis. Rev Eletron Adm Tur. 2013; 2(1):93-109.

35. Figueiredo AM. Formação de pessoal qualificado no Brasil: limitações estruturais do sistema de ensino. ComCiência [Internet]. 2013; 148 [acesso 2015 Fev 12]. Disponível em: http://comciencia.scielo.br/scielo.php?script=sci_arttext\&pid=S1519$76542013000400009 \&$ lng $=$ pt\&nrm $=$ iso 
Luz MMA, Romero ABR, Brito AKS, Batista LPR, Nogueira LT, Santos MM, et al. La formación del profesional nutricionista en la percepción del docente. Interface (Botucatu). 2015; 19(54):589-601.

Este estudio evaluó la formación del profesional de nutrición en la percepción de los docentes nutricionistas de una institución de Enseñanza Superior del nordeste brasileño. Se trata de encuesta cualitativa realizada con veinte profesores nutricionistas que dictaran asignaturas del ciclo de profesionalización en el período de 1980 a 2008. La principal limitación fue la deficiencia de infraestructura física, de material y de equipos, principalmente para la realización de clases prácticas. Se mencionaron las limitaciones relacionadas con la actividad docente y con el conocimiento adquirido por los estudiantes. A pesar de las dificultades señaladas, se refirieron mejoras estructurales. Son necesarias adecuaciones adicionales en la infraestructura, así como medidas enfocadas en una mejor planificación del trabajo docente y para la toma de conciencia del cuerpo discente de su papel en el proceso enseñanza-aprendizaje, posibilitando la formación de profesionales más capacitados para el mercado de trabajo.

Palabras clave: Enseñanza superior. Docentes. Nutricionista. 
